\title{
Consumo, digestibilidade dos nutrientes e características ruminais de cordeiros alimentados com níveis crescentes de concentrado em ambiente tropical no Vale do Alto Guaporé - MT
}

\author{
Intake, apparent digestibility and ruminal characteristics of \\ the lambs fed with increasing levels of concentrate in tropical \\ environment in the Valley of Guaporé - MT
}

\author{
Luiz Juliano Valério Geron ${ }^{1 *}$; Alexandre Agostinho Mexia ${ }^{1}$; Renato Lima Cristo ${ }^{2}$; \\ Jocilaine Garcia ${ }^{1}$; Luciano da Silva Cabral ${ }^{1}$; Raquel Joana Trautmann ${ }^{1}$; \\ Osvaldo de Souza Martins ${ }^{1}$; Lúcia Maria Zeoula ${ }^{3}$
}

\begin{abstract}
Resumo
Objetivou-se avaliar níveis crescentes de concentrado na dieta de cordeiros sobre o consumo e coeficiente de digestibilidade total (CD) dos nutrientes, características ruminais, temperatura corporal e retal. Foram utilizados quatro cordeiros sem raça definida (SRD), não castrados, com peso corporal (PC) médio de 19,3 $\mathrm{Kg} \pm 2,07$ por meio de um delineamento em quadrado latino 4 x 4. Os animais foram alojados em gaiolas de metabolismo, os quais foram alimentados duas vezes ao dia, com dieta composta por silagem de milho e concentrado, na proporção de 20, 40, 60 e $80 \%$ na matéria seca da dieta, as quais eram compostas por milho grão moído e farelo de soja. Diariamente as sobras foram monitoradas e as fezes foram coletadas por meio de sacolas de napa. Os dados das variáveis estudadas foram submetidos à ANOVA e análise de regressão a $5 \%$ de probabilidade. Os níveis crescentes de concentrado nas rações de cordeiros alteraram $(\mathrm{P}<0,05)$ de maneira linear decrescente o consumo de FDN e FDA e de forma quadrática o consumo de MS, MO, PB, EE, CHT e CNF. Não houve efeito ( $\mathrm{P}>0,05)$ dos níveis de concentrado sobre o coeficiente de digestibilidade da MS, MO, EE, FDN, FDA, CHT e CNF. Entretanto, o coeficiente de digestibilidade da $\mathrm{PB}$ apresentou efeito quadrático $(\mathrm{P}<0,05)$. Os valores de $\mathrm{pH}$ e nitrogênio amoniacal apresentaram efeito quadrático $(\mathrm{P}<0,05)$ para o tempo após a alimentação. A temperatura corporal e retal dos cordeiros não foi influenciada $(\mathrm{P}>0,05)$ pelos níveis de concentrado na dieta. Conclui-se que $38 \%$ de concentrado nas rações de cordeiros favorece o máximo consumo de matéria seca, matéria orgânica e proteína bruta. $\mathrm{O}$ coeficiente de digestibilidade dos nutrientes, exceto para proteína bruta, não são alterados com a adição de até $80 \%$ de concentrado na dieta de cordeiros, bem como este não afeta o pH e a concentração de nitrogênio amoniacal do líquido ruminal, temperatura corporal e retal.
\end{abstract}

Palavras-chave: Carboidrato, gordura, $\mathrm{pH}$, nitrogênio amoniacal, temperatura retal

\footnotetext{
Abstract

The objective was to evaluate the use of concentrate in the diet of lambs on intake and total digestibility

${ }^{1}$ Profs. da Universidade do Estado de Mato Grosso, UNEMAT, Pontes e Lacerda, MT. E-mail: ljgeron@yahoo.com.br; alexandre@ unemat.br; jo@unemat.br; cabralls@ufmt.br; raquel_trautmann@hotmail.com; osvsou@unemat.br

${ }^{2}$ Discente da UNEMAT, Pontes e Lacerda, MT. E-mail: renatto-lima_@hotmail.com

${ }^{3}$ Prof $^{a}$ da Universidade Estadual de Maringá, UEM, Maringá, PR. E-mail: lmzeoula@uem.br

* Autor para correspondência
} 
coefficient (DC) of nutrients, ruminal characteristics, rectal and body temperature. It was used four lambs without breed defined (SRD), entire, with average body weight (BW) of $19.3 \pm 2.07 \mathrm{~kg}$ using a Latin square design, $4 \times 4$. The animals were housed in metabolism cages and were fed twice a day with diet consisting of corn silage and concentrate at a ratio of $20,40,60$ and $80 \%$ dry matter in the diet, composite of corn grains and soybean meal. Leftovers were measured daily and the feces were collected through bags. Data from variables studied were submitted to ANOVA and regression analysis at $5 \%$ probability. The increasing levels of concentrate in lamb diets affected $(\mathrm{P}<0.05)$ of linear form decreasing the intake of NDF, ADF and quadratic of DM, OM, CP, EE, NFC and TCH intake. There was no effect $(\mathrm{P}>0.05)$ of concentrate levels on digestibility coefficient of DM, OM, EE, NDF, ADF, NFC and TCH. However, the digestibility coefficient of CP showed a quadratic effect $(\mathrm{P}<0.05)$. The $\mathrm{pH}$ and ammonia nitrogen showed a quadratic effect $(\mathrm{P}<0.05)$ for the time after feeding. The rectal and body temperature of lambs was not affected $(\mathrm{P}>0.05)$ by dietary concentrate. It can be concluded that $38 \%$ of concentrate in diets of lambs favors the maximum dry matter intake, organic matter and crude protein. The digestibility coefficient of the nutrients, except for protein, are not altered with the addition up to $80 \%$ concentrate in diet for lambs, as well as, this does not affect the $\mathrm{pH}$ and ammonia nitrogen concentration of ruminal fluid, rectal and body temperature.

Key words: Ammonia nitrogen, carbohydrate, fat, $\mathrm{pH}$, rectal temperature

\section{Introdução}

A produção de cordeiros em sistema de confinamento tem sido estimulada para atender as exigências do mercado consumidor por carcaças de melhor qualidade, além de ser uma alternativa para produzir carne de forma precoce e competitiva (GERON et al., 2012). A terminação de cordeiros em confinamento, além de proporcionar o fornecimento de dietas mais adequadas em termos nutricionais aos animais, pelo fato da alimentação ser controlada no cocho, minimiza a ocorrência de verminose, decorrente da infestação provocada pelos endoparasitas das pastagens, permitindo aos cordeiros maior ganho médio diário (CASTRO et al., 2007) e reduz as perdas de animais jovens por deficiências nutricionais do pasto, no período seco do ano (BARROS; VASCONCELOS; ARAÚJO, 2003).

$\mathrm{O}$ uso de dietas com maiores teores em nutrientes, no sentido de permitir maior desempenho dos animais, pode proporcionar aumento no investimento de produção, o que representa riscos para viabilidade econômica da atividade (GERON et al., 2012).

O efeito da inclusão de concentrado na dieta total de animais ruminantes sobre o consumo tem sido estudado por diversos autores (MAEDA et al.,
2007; MORENO et al., 2010); e, segundo Zambom et al. (2005), a resposta animal aos níveis de concentrado dietéticos tem sido curvilínea. Assim, o ponto ótimo de concentrado na dieta é variável e tem como fatores determinantes o sexo, a raça, a idade, a qualidade do volumoso e do concentrado (MEDEIROS et al., 2007).

Entre os fatores envolvidos na regulação do consumo, a concentração de fibra em detergente neutro (FDN) da dieta de ruminantes tem sido considerada, em função de sua lenta degradação e baixa taxa de passagem através do ambiente ruminal. Sendo assim, se a ingestão é limitada pela ocupação de espaço no trato gastrintestinal, alimentos com alto teor de FDN, como os volumosos, poderão ter a sua ingestão restringida, limitando, com isso, a expressão do potencial genético do animal para produção (CARVALHO, et al., 2006), por outro lado, quando se utilizam rações com baixa proporção de FDN e alto teor de energia, a demanda energética do animal pode ser suprida em níveis menores de ingestão (MERTENS, 1994; CARDOSO et al., 2006).

Segundo Moreno et al. (2010) e Cruz et al. (2011), a ingestão e a digestibilidade dos nutrientes podem estar correlacionados de maneira positiva ou negativa entre si, o que depende da qualidade 
da dieta, comumente referidos como efeitos associativos. Normalmente, a correlação entre a ingestão e a digestibilidade dos nutrientes é positiva em ditas com elevada proporção de volumoso de baixa qualidade, uma vez que o volume ocupado pela fração fibrosa de baixa digestibilidade reduz a ingestão de matéria seca (VAN SOEST, 1994).

Dietas com alto teor de concentrado tornaram se economicamente viáveis, nos últimos anos, em função da elevação no custo de produção de volumosos, redução no preço dos concentrados e ao aumento da oferta de co-produtos da indústria (BORGES et al., 2011; GERON et al., 2011).

Algumas hipóteses indicam que a alimentação menos frequente (RIBEIRO et al., 2011) e a maior concentração de carboidratos de fácil fermentação ruminal na dieta de animais ruminantes, levam ao aumento da variação das características ruminais ao longo do dia, sendo que a redução dessa variação é desejável para melhorar o desempenho animal (ZEOULA et al., 2003).

As diferentes proporções de ingredientes volumosos e concentrados, a freqüência de alimentação e a sincronização das fontes de proteína e carboidratos da dieta de ruminantes podem alterar o processo de fermentação ruminal, a concentrações de ácidos graxos voláteis e de nitrogênio amoniacal do fluído ruminal, a flutuação do $\mathrm{pH}$ ruminal e a digestão da fibra (ZEOULA et al., 2006; MAEDA et al., 2007).

A utilização de alimentos volumosos também é importante nas dietas de ruminantes em confinamento, pois a fibra é essencial para estimular a mastigação e ruminação (VAN SOEST, 1994). Dietas que não estimulam adequadamente a mastigação reduzem a produção de saliva, resultando em diminuição do $\mathrm{pH}$ ruminal e, conseqüente, redução da digestibilidade da fibra (MAEDA et al., 2007).

A produção de ovinos em região tropical do Brasil pode levar os animais ao estresse calórico, o qual é um fator que limita a produção de ovinos e sua causa está correlacionada com as altas temperaturas ambiente, desta forma o ajuste da prática de manejo, horário de arraçoamento da dieta, quantidades de refeições, utilização de ambiente com sombra podem ocasionar melhora no sistema de produção (NEIVA et al., 2004; NEVES et al., 2009), além do controle mais preciso das variáveis ambientais como temperatura do ar, umidade relativa do ar e velocidade do vento (EUSTÁQUIO FILHO et al., 2011).

Desta maneira, objetivou-se avaliar o consumo, coeficiente de digestibilidade total dos nutrientes, parâmetros ruminais, temperatura corporal e retal de cordeiros mantidos em ambiente tropical alimentados com rações contendo níveis crescentes de concentrado.

\section{Material e Métodos}

O estudo foi conduzido no Campus Universitário de Pontes e Lacerda no Setor de Metabolismo Animal (SeMA) pertencente à Universidade do Estado de Mato Grosso (UNEMAT) e no Laboratório de Análise de Alimentos e Nutrição Animal (LAANA) da UNEMAT, situados a $15^{\circ}$ 19' 05" de latitude Sul e 59 13 ' 26" de longitude Oeste e a uma altitude de 295 metros. O clima da região do Vale do Alto Guaporé - MT é classificado como Tropical Continental, alternadamente úmido e seco do tipo Aw segundo Koppen (SEPLAN, 2007). Foram utilizados quatro cordeiros sem raça definida, com peso corporal (PC) inicial médio de 19,3 $\pm 2,1$ $\mathrm{kg}$, em ensaio de digestibilidade total. Os cordeiros foram alojados em gaiolas de metabolismo, as quais possuíam comedouros e bebedouros individuais. Quinze dias antes do início do período experimental os cordeiros foram everminados via oral com o produto a base de "closantel", conforme recomendação do fabricante.

Foi utilizado delineamento experimental em quadrado latino (4X4) com quatro animais, quatro períodos e quatro dietas experimentais com diferentes níveis de inclusão de concentrado na 
dieta de cordeiros para avaliar os seus efeitos sobre o consumo e o coeficiente de digestibilidade total dos nutrientes, as características ruminais e a temperatura corporal externa e retal.

Os alimentos concentrados utilizados no preparo das rações experimentais foram o milho grão moído (MG) e o farelo de soja (FS), e como alimento volumoso foi utilizado a silagem de milho (SM). A composição bromatológica dos alimentos está apresentada na Tabela 1 .

Tabela 1. Composição bromatológica dos alimentos experimentais.

\begin{tabular}{lcccccccc}
\hline \multirow{2}{*}{ Alimento } & \multirow{2}{*}{ MS \% } & \multicolumn{7}{c}{ Nutrientes expressos em \% da MS } \\
\cline { 3 - 9 } & & MO & PB & EE & FDN & FDA & MM & NDT $^{1}$ \\
\hline SM & 24,26 & 93,24 & 7,30 & 2,25 & 57,43 & 38,48 & 6,76 & 63,13 \\
MG & 89,98 & 98,45 & 9,10 & 4,20 & 15,57 & 5,88 & 1,55 & 86,44 \\
FS & 88,62 & 92,71 & 50,00 & 1,16 & 14,44 & 10,41 & 7,29 & 88,73 \\
\hline
\end{tabular}

SM: silagem de milho; MG: milho grão moído; FS: farelo de soja; MS: matéria seca; MO: matéria orgânica; PB: proteína bruta; EE: extrato etéreo; FDN: fibra em detergente neutro; FDA: fibra em detergente ácido; MM: matéria mineral e ${ }^{1}$ NDT: nutrientes digestíveis totais, obtidos segundo Sniffen, O’Connor e Van Soest (1992).

Fonte: Elaboração dos autores.

As rações experimentais apresentaram os (isoprotéica - NRC, 1985) e o valor de nutrientes seguintes níveis de concentrado $20 \% ; 40 \% ; 60 \%$ e $80 \%$, respectivamente na MS. As rações foram balanceadas para apresentar $13,0 \%$ de proteína bruta digestíveis totais foi varável (linear crescente) conforme ocorreu inclusão do concentrado nas rações experimentais (Tabela 2).

Tabela 2. Composição percentual e bromatológica das rações experimentais.

\begin{tabular}{|c|c|c|c|c|}
\hline \multirow{2}{*}{ Alimentos } & \multicolumn{4}{|c|}{ Níveis crescentes de concentrado nas rações experimentais } \\
\hline & $20 \%$ & $40 \%$ & $60 \%$ & $80 \%$ \\
\hline \multicolumn{5}{|c|}{ Composição percentual das rações experimentais } \\
\hline SM & 80 & 60 & 40 & 20 \\
\hline MG & 8 & 28,5 & 49 & 69,5 \\
\hline FS & 12 & 11,5 & 11 & 10,5 \\
\hline Total & 100,0 & 100,0 & 100,0 & 100,0 \\
\hline \multicolumn{5}{|c|}{ Composição bromatológica (\% na MS) das rações experimentais } \\
\hline MS & 37,24 & 50,39 & 63,54 & 76,69 \\
\hline MO & 93,59 & 94,66 & 95,73 & 96,81 \\
\hline $\mathrm{PB}$ & 12,57 & 12,72 & 12,88 & 13,03 \\
\hline $\mathrm{EE}$ & 2,27 & 2,68 & 3,08 & 3,49 \\
\hline FDN & 48,92 & 40,56 & 32,19 & 23,82 \\
\hline FDA & 32,50 & 25,96 & 19,42 & 12,88 \\
\hline CHT & 78,75 & 79,26 & 79,77 & 80,28 \\
\hline $\mathrm{CNF}$ & 29,83 & 38,70 & 47,58 & 56,46 \\
\hline $\mathrm{NDT}^{1}$ & 68,07 & 72,72 & 77,37 & 82,02 \\
\hline
\end{tabular}

SM: silagem de milho; MG: milho grão moído; FS: farelo de soja; MS: matéria seca; MO: matéria orgânica; PB: proteína bruta; EE: extrato etéreo; FDN: fibra em detergente neutro; FDA: fibra em detergente ácido; CHT: carboidratos totais; CNF: carboidratos não fibrosos e ${ }^{1}$ NDT: nutrientes digestíveis totais, estimados segundo Sniffen, O’Connor e Van Soest (1992).

Fonte: Elaboração dos autores. 
Os cordeiros tiveram acesso à água por meio de bebedouros individuais. Diariamente, foram fornecidos $10 \mathrm{~g}$ de mistura mineral por animal, que foi adicionada diretamente sobre aos concentrados experimentais no momento da oferta das dietas, ou seja, duas vezes ao dia (5 $\mathrm{g}$ de sal refeição- $\mathrm{O}^{-1}$ animal $\left.^{-1}\right)$. A composição química do sal mineral

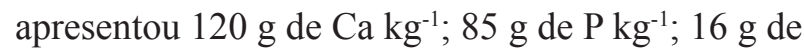
$\mathrm{S} \mathrm{kg}^{-1} ; 148 \mathrm{~g}$ de $\mathrm{Na} \mathrm{kg}^{-1} ; 50 \mathrm{mg}$ de $\mathrm{Co} \mathrm{kg}^{-1} ; 500 \mathrm{mg}$ de $\mathrm{Cu} \mathrm{kg}{ }^{-1} ; 16$ mg de Se kg-1 e 4.800 mg de $\mathrm{Zn} \mathrm{kg}^{-1}$.

A oferta das dietas (rações experimentais) foi realizada ad libitum (à vontade) de maneira que houvesse aproximadamente $10 \%$ de $\mathrm{MN}$ de sobras, diariamente, a qual foi fracionada em duas refeições ao dia, fornecidas às $7 \mathrm{~h}: 00 \mathrm{~min}$ e às $17 \mathrm{~h}: 00 \mathrm{~min}$. $\mathrm{O}$ monitoramento das sobras foi realizado diariamente, antes do primeiro trato.

$\mathrm{O}$ ensaio de digestibilidade total dos nutrientes teve duração de 80 dias, divididos em quatro períodos experimentais com duração de 20 dias, sendo 14 dias para adaptação dos animais e 6 dias para coletas de amostras de sobras e fezes. Durante os períodos de coletas foram realizadas coletas totais de fezes, alimentos fornecidos, sobras e do líquido ruminal, sendo o último coletado por meio de uma sonda esofágica e bomba elétrica de sucção a vácuo. Nos períodos de adaptação e coleta, o manejo foi realizado conforme descrito por Silva e Leão (1979).

Para proceder a coleta total de fezes, em cada cordeiro foi adaptada uma sacola de napa para coleta total de fezes durante o período experimental. As fezes de cada animal foram pesadas diariamente pela manhã e homogeneizadas, sendo retiradas amostras compostas, correspondentes a $10 \%$ de seu peso total. As amostras foram acondicionadas em sacos plásticos, identificadas por animal e período experimental e armazenadas em freezer com temperatura a $-10^{\circ} \mathrm{C}$, para posterior análise.

No último dia de cada período experimental de coleta foi realizada a amostragem do líquido ruminal. Foram realizadas cinco coletas de líquido ruminal por animal, nos tempos: 0 (antes da alimentação), 2, 4, 6 e 8 horas (após a primeira alimentação - refeição). Foi utilizada uma bomba de vácuo com pressão de $40 \mathrm{~mm} \mathrm{Hg}$, e uma sonda de silicone com 2,0 metros de comprimento por $12 \mathrm{~mm}$ de diâmetro, que foi lubrificada com óleo mineral (Nujol) antes de ser introduzida pela boca do animal (ZEOULA et al., 2003). Foram retirados aproximadamente $100 \mathrm{~mL}$ de líquido do rúmen de cada animal para que ao ser filtrado com um tecido duplo de algodão, sobrasse em torno de $80 \mathrm{~mL}$. Estes foram homogeneizados e com o potenciômetro foi mensurado o valor de $\mathrm{pH}$ imediatamente após cada coleta de líquido ruminal. Em seguida, aproximadamente $50 \mathrm{~mL}$ do líquido ruminal foi transferido para um frasco com $1 \mathrm{~mL}$ de $\mathrm{H}_{2} \mathrm{SO}_{4}(\mathrm{PA}-98,0 \%)$ para cessar a fermentação. Essa amostra do líquido ruminal foi utilizada para determinação da concentração de nitrogênio amoniacal $\left(\mathrm{N}-\mathrm{NH}_{3}\right)$, conforme recomendações de Fenner (1965), modificados por Vieira (1980).

As amostras de alimentos, sobras e fezes foram secas em estufa a $55{ }^{\circ} \mathrm{C}$ por 72 horas e processadas em moinho de facas utilizando-se peneira de crivos de $1 \mathrm{~mm}$, sendo em seguida homogeneizadas em quantidades iguais, com base no peso seco, para formar amostras compostas de fezes e sobras animal $^{-1}$ período $^{-1}$ ração experimental $^{-1}$.

O teor de nitrogênio dos alimentos estudados, das sobras e fezes foi obtido pelo método semi-microKjeldahl, usando 6,25 como fator de conversão para $\mathrm{PB}$, a matéria mineral (MM) foram realizadas pelo método por incineração em mufla a $600{ }^{\circ} \mathrm{C}$, o teor de matéria orgânica (MO) foi estimado por diferença $(100-\mathrm{MM})$ e o teor de extrato etéreo (EE) foi determinado pela extração por lavagem com éter de petróleo, segundo citações de Silva e Queiroz (2002).

A determinação da fibra em detergente neutro (FDN) e da fibra em detergente ácido (FDA) dos alimentos, sobras e fezes foi realizada de acordo com Van Soest et al. (1991), sem a utilização de sulfito e sem corrigir os valores de FDN e FDA com relação 
ao teor de matéria mineral da fibra. A determinação dos carboidratos totais (CHT) dos alimentos, sobras e fezes foi obtida pela equação $\mathrm{CHT}=\mathrm{MO}-[\mathrm{EE}+$ PB] de acordo com Sniffen, O'Connor e Van Soest (1992).

Os teores de nutrientes digestíveis totais (NDT) das rações experimentais foi obtido pela equação de Sniffen, O'Connor e Van Soest (1992) onde $\mathrm{NDT}=\mathrm{PBD}+2,25 \mathrm{EED}+\mathrm{CHTD}(\mathrm{PBD}$; proteína digestível; EED: extrato etéreo digestível e CHTD: carboidrato total digestível).

No último dia de cada período experimental foram determinadas as temperaturas corporais e retais dos animais, por meio de termômetros digitais. A temperatura corporal externa e retal foi coletada a cada três horas durante o último dia de coleta de cada período experimental.

As variáveis estudadas foram submetidas à análise de variância por intermédio do software SAEG (UFV, 1997), considerando valor de "P" de 0,05 . Quando verificada significância de efeitos dos níveis de concentrados, foi procedida análise de regressão, considerando os efeitos linear e quadrático, sendo a escolha do modelo realizada a partir dos valores de "P" e " $\mathrm{R}$ ". Para as variáveis pH e concentração de amônia no líquido ruminal a análise estatística foi procedida considerando a subdivisão da parcela, considerando os tempos de avaliação após a alimentação dos animais.

\section{Resultados e Discussão}

O fornecimento de níveis crescentes de concentrado nas rações de cordeiros alterou de forma quadrática $(\mathrm{P}<0,05)$ o consumo de $\mathrm{MS}, \mathrm{MO}$, $\mathrm{PB}$ e EE expressos em $\mathrm{g} \mathrm{dia}{ }^{-1}$; \% PC e $\mathrm{g} \mathrm{kg}^{0,75-1}$ (Tabela 3). O consumo máximo de MS foi de 575,92 $\mathrm{g} \mathrm{dia}^{-1} ; 3,66 \%$ PC e $69,79 \mathrm{~g} \mathrm{~kg}^{0,75-1}$ estimados pelas equações apresentadas na Tabela 3, para os níveis de $35 \% ; 39 \%$ e $38 \%$ de concentrado nas rações, respectivamente.
Este efeito quadrático da inclusão do concentrado sobre o consumo de nutrientes era esperado, uma vez que o consumo elevado de carboidratos não fibrosos (amido) em animais ruminantes pode causar efeito associativo negativo, além de reduzir o $\mathrm{pH}$ do líquido ruminal e, conseqüentemente, reduzir o consumo de MS (ZEOULA et al., 2003). Outro fato que pode ter contribuído para este efeito quadrático no consumo de MS está correlacionado com a maior ou menor estabilidade aeróbia da silagem, pois, quando esta é fornecida nos cochos, entra em contato com o ar, deteriorando-se e perdendo nutrientes (GIMENES et al., 2006), podendo ser rejeitada pelos animais. Outro fator que geralmente influencia o consumo em confinamentos é o numero de refeições realizadas por dia, uma vez que os animais são estimulados a ingerir MS quando se realiza o arraçoamento. No presente estudo foram realizadas duas refeições diárias (7:00 e 17:00 horas).

A composição bromatológica da silagem de milho está demonstrada na Tabela 1 , e pode ser observado que o teor de MS foi de 24,26\%, o que pode ter contribuído para acelerar a oxidação da mesma no cocho e consequentemente, ter diminuído a qualidade deste ingrediente durante o período de 24 horas (dia) e assim ter interferido no consumo de MS das rações contendo maior proporção de volumoso.

Adicionalmente, pode ser considerado que o aumento dos níveis de concentrado implica em redução dos teores de FDN e, conseqüentemente, aumento dos teores de NDT. Desta maneira, pode-se inferir que nestas condições o consumo dos animais foi regulado pela teoria fisiológica e não pelo enchimento ruminal (MERTENS, 1994). Desta forma, o consumo das dietas tende a decrescer a partir de determinada concentração de energia (metabolizável ou NDT), quando atingida a capacidade máxima dos animais em utilizarem a energia da dieta. 
Tabela 3. Consumo médio diário de matéria seca (CMS), matéria orgânica (CMO), proteína bruta (CPB), extrato etéreo (CEE), fibra em detergente neutro (CFDN) e ácido (CFDA), carboidratos totais (CCHT) e carboidratos não fibrosos (CCNF) por cordeiros alimentados com dietas contendo níveis crescentes de concentrado.

\begin{tabular}{|c|c|c|c|c|c|c|}
\hline \multirow{2}{*}{ Variáveis } & \multicolumn{4}{|c|}{ Níveis crescentes de concentrado nas rações experimentais } & \multirow{2}{*}{ Regressão } & \multirow{2}{*}{$\begin{array}{l}\text { CV } \\
(\%)\end{array}$} \\
\hline & $20 \%$ & $40 \%$ & $60 \%$ & $80 \%$ & & \\
\hline CMS g kg & 64,38 & 71,23 & 60,86 & 43,29 & 1 & 14,94 \\
\hline CMS \% PCV & 3,15 & 3,54 & 3,01 & 2,12 & 2 & 16,18 \\
\hline CMS g dia ${ }^{-1}$ & 549,46 & 580,56 & 503,70 & 366,42 & 3 & 12,01 \\
\hline $\mathrm{CMO} \mathrm{g} \mathrm{dia}^{-1}$ & 516,06 & 553,24 & 483,94 & 345,35 & 4 & 12,15 \\
\hline CPB $g$ dia $^{-1}$ & 73,02 & 77,37 & 71,51 & 46,48 & 5 & 8,15 \\
\hline CEE g dia ${ }^{-1}$ & 13,98 & 16,60 & 16,34 & 10,02 & 6 & 22,84 \\
\hline CFDN \% PCV & 1,54 & 1,45 & 0,94 & 0,35 & 7 & 15,24 \\
\hline CFDN g dia ${ }^{-1}$ & 268,44 & 238,65 & 158,74 & 61,27 & 8 & 18,29 \\
\hline CFDA g $\mathrm{dia}^{-1}$ & 176,59 & 142,89 & 83,82 & 52,79 & 9 & 17,69 \\
\hline CCHT g dia ${ }^{-1}$ & 327,37 & 345,13 & 289,76 & 206,73 & 10 & 13,69 \\
\hline CCNF g dia ${ }^{-1}$ & 160,62 & 226,05 & 237,34 & 227,59 & 11 & 17,26 \\
\hline
\end{tabular}

${ }^{1} \mathrm{Y}=47,836+1,15773 \mathrm{X}-0,0152609 \mathrm{X}^{2}\left(\mathrm{R}^{2}=70,80 \%\right)$ ${ }^{2} \mathrm{Y}=2,27709+0,06142 \mathrm{X}-0,00079586 \mathrm{X}^{2}\left(\mathrm{R}^{2}=67,04 \%\right)$;

${ }^{3} \mathrm{Y}=446,0550+7,39372 \mathrm{X}-0,105236 \mathrm{X}^{2}\left(\mathrm{R}^{2}=68,09 \%\right)$;

${ }^{4} \mathrm{Y}=400,291+8,07869 \mathrm{X}-0,109859 \mathrm{X}^{2}\left(\mathrm{R}^{2}=68,94\right)$;

${ }^{5} \mathrm{Y}=51,7241+1,40964 \mathrm{X}-0,0183705 \mathrm{X}^{2}\left(\mathrm{R}^{2}=73,21 \%\right)$;

${ }^{6} \mathrm{Y}=6,10122+0,49783 \mathrm{X}-0,00558606 \mathrm{X}^{2}\left(\mathrm{R}^{2}=60,11 \%\right)$;

${ }^{7} \mathrm{Y}=2,08779-0,0202712 \mathrm{X}\left(\mathrm{R}^{2}=85,14 \%\right) ;$

${ }^{8} \mathrm{Y}=357,124-3,5072 \mathrm{X}\left(\mathrm{R}^{2}=85,70 \%\right)$

${ }^{9} \mathrm{Y}=221,643-2,1524 \mathrm{X}\left(\mathrm{R}^{2}=88,40 \%\right)$;

${ }^{10} \mathrm{Y}=270,589+4,21262 \mathrm{X}-0,0629907 \mathrm{X}^{2}\left(\mathrm{R}^{2}=68,50 \%\right) ;$

${ }^{11} \mathrm{Y}=65,8835+5,75945 \mathrm{X}-\left(0,0469851 \mathrm{X}^{2}\left(\mathrm{R}^{2}=58,11 \%\right)\right.$.

$\mathrm{g} \mathrm{kg}^{0,75-1}$ : gramas por quilograma de peso metabolico; \%PCV: percentagem do peso corporal vivo; $\mathrm{g} \mathrm{dia}^{-1}$ : grama por dia e $\% \mathrm{CV}$ : coeficiente de variação.

Fonte: Elaboração dos autores.

Moreno et al. (2010) avaliaram diferentes proporções de volumoso e concentrado na dieta de cordeiros e observaram que o consumo de MS (867 $\mathrm{g} \mathrm{dia}^{-1}$ e 79,86 $\left.\mathrm{g} \mathrm{kg}^{0,75-1}\right)$ foi máximo $(\mathrm{P}<0,05)$ para as dietas com $60 \%$ de concentrado. A diferença de consumo máximo de MS observado pelos pesquisadores citados e os obtidos no presente trabalho pode ser explicada pela diferença no potencial genético dos animais.

Em estudo realizado por Carvalho et al. (2006), para avaliar o comportamento ingestivo de ovinos alimentados com dietas compostas de silagem de capim-elefante amonizada ou não e subprodutos agroindustriais em dieta contendo $60 \%$ de volumoso e $40 \%$ de concentrado, os pesquisadores observaram que os resíduos da agroindústria aumentaram o teor de FDN da dieta, porém este não influenciou o tempo de ruminação e ócio dos animais e a ingestão de $\mathrm{MS} g \operatorname{dia}^{-1}$ em relação à dieta padrão sem subproduto da agroindústria.

A avaliação do comportamento ingestivo em relação à freqüência de alimentação em ovinos foi realizado por Ribeiro et al. (2011), os quais observaram que não houve diferença $(\mathrm{P}>0,05)$ para o tempo de ingestão, ruminação e ócio dos ovinos alimentados com uma, duas ou três refeições diárias.

De acordo com Cardoso et al. (2006), os tempos despendidos em ingestão, ruminação, ócio e mastigação total não foram alterados $(\mathrm{P}>0,05)$ em função do nível de FDN (25\%; 31\%; 37\% e $43 \%$ ) nas dietas de ovinos. Assim, concluíram que o nível igual e inferior a $44 \%$ de FDN na dieta de cordeiros confinados não exerce influência sobre os tempos despendidos pelos animais em ingestão, ruminação e ócio. Porém, as dietas do presente estudo apresentaram variação de $48,9 \%$ a $23,8 \%$ de FDN na MS. Desta maneira, estes valores de FDN podem ter interferido no tempo de ingestão da MS 
e conseqüentemente ter alterado a qualidade da silagem no cocho devido ao tempo de exposição da silagem ao ar.

O consumo de $\mathrm{MO}$ e PB apresentaram ponto de máximo para os níveis de $37 \%$ e $38 \%$ de concentrado na ração com valores de 548,80 $\mathrm{g} \mathrm{dia}^{-1}$ e 78,76 g dia $^{-1}$, respectivamente. Entretanto, Moreno et al. (2010) não observaram efeito $(\mathrm{P}>0,05)$ dos níveis crescentes de concentrado sobre o consumo de $\mathrm{MO}$ e PB $\left(\mathrm{g} \mathrm{dia}^{-1}\right)$ em cordeiros.

Estudo realizado por Zeoula et al. (2003), em ovinos recebendo proporções elevadas de concentrado na dieta contendo carboidrato de fácil fermentação (amido de mandioca) permitiu consumo de elevada quantidade de carboidratos solúveis, o que provocou distúrbios digestivos nos animais, caracterizados por declínio no $\mathrm{pH}$ ruminal. Tal evento pode ter afetado negativamente as bactérias ruminais, causando com isso redução da digestão da fibra e do consumo de MS da dieta total.

A interação entre o alimento volumoso e concentrado no rúmen pode causar um efeito associativo que promove uma série de modificações na digestibilidade e no consumo de matéria seca e demais nutrientes, o que pode afetar o desempenho animalde maneira positiva ou negativa(VANSOEST, 1994). Assim, a adição de alimentos concentrados (grãos de cereais e farelos de oleaginosas), nas dietas de animais ruminantes, causam alterações no equilíbrio ruminal ( $\mathrm{pH}$ e concentração de nitrogênio amoniacal), devido ao aumento significativo de nutriente mais solúveis no rúmen, principalmente os carboidratos de rápida fermentação (amido) (ZEOULA et al., 2006) interferindo no consumo e no coeficiente de digestibilidade da $\mathrm{MO}$ e PB da dieta.

Os níveis crescentes de concentrado alteraram o consumo de EE g dia ${ }^{-1}$ de maneira quadrática $(\mathrm{P}<0,05)$ com ponto de máximo para o nível de concentrado $45 \%$ e valor estimado de consumo de 17,19 $\mathrm{g}$ animal $^{-1} \mathrm{dia}^{-1}$. Da mesma maneira, Moreno et al. (2010) observaram que rações com $40 \%$ de concentrado estimularam $(\mathrm{P}<0,05)$ o consumo de $\mathrm{EE} \mathrm{g} \mathrm{dia}^{-1}$ em cordeiros em relação às demais rações experimentais.

O fornecimento de níveis crescentes de concentrado nas rações de cordeiros reduziu $(\mathrm{P}<0,05)$ linearmente o consumo de FDN e FDA em 3,50 e 2,15 $\mathrm{g} \mathrm{dia}^{-1}$, respectivamente, enquanto que para o consumo de CHT e CNF foi observado comportamento quadrático $(\mathrm{P}<0,05)$ com a inclusão do concentrado, sendo estimados valores máximos de 341,02 e $242,38 \mathrm{~g} \mathrm{dia}^{-1}$, para os níveis de concentrado de 33,43 e $61,29 \%$ (Tabela 3 ).

O comportamento linear decrescente para a ingestão da FDN e FDA para as rações contendo os diferentes níveis de concentrado, pode ter ocorrido devido aos alimentos concentrados apresentarem menores teores destes componentes nutricionais em relação ao volumoso (silagem de milho) como apresentado na Tabela 1.

Pode-se verificar na literatura que o consumo de dietas com altos teores de fibra é controlado por fatores físicos, como a taxa de passagem e enchimento ruminal, ao passo que em dietas comaltos teores de concentrado (alta densidade energética), o consumo é controlado fatores metabólicos (NRC, 1996) e pela demanda energética (CARDOSO et al., 2006). Este fato pode ser comprovado na Tabela 2 , na qual observou que as rações com maiores níveis de concentrado apresentaram maior teor de NDT.

O comportamento quadrático observado para o consumo de CNF em função dos níveis de concentrado confirma que a alta ingestão de concentrado pode causar efeito associativos negativos, além de propiciar redução no $\mathrm{pH}$ do líquido ruminal e consequentemente alterar a ingestão de materia seca e demais nutrientes (ZEOULA et al., 2003). Porém, Moreno et al. (2010), não observaram $(\mathrm{P}>0,05)$ diferenças no consumo de CHT e CNF em cordeiros alimentados com teores variando de 40 a $60 \%$ de concentrado, com valores médios de 591,84 $\mathrm{g} \mathrm{dia}^{-1}$ e 471,43 g dia $^{-1}$, respectivamente. 
O fornecimento de níveis crescentes de concentrado nas rações de cordeiros não alterou $(\mathrm{P}>0,05)$ o coeficiente de digestibilidade da MS, MO, EE, FDN, FDA, CHT e CNF (Tabela 4), com valores médios de 58,41\%; 61,32\%;
$80,79 \% ; \quad 48,08 \% ; \quad 37,12 \%, 47,89 \%$ e $72,68 \%$, respectivamente. Porém, os níveis crescentes de concentrado propiciaram um efeito quadrático $(\mathrm{P}<0,05)$ sobre o coeficiente de digestibilidade da PB.

Tabela 4. Coeficientes de digestibilidade total (CD) da matéria seca (MS), matéria orgânica (MO), proteína bruta (PB), extrato etéreo (EE), fibra em detergente neutro (FDN) e ácido (FDA), carboidrato total (CHT) e carboidrato não fibroso (CNF) para os cordeiros alimentados com rações contendo diferentes níveis de concentrado e coeficientes de variação $(\mathrm{CV})$.

\begin{tabular}{lcccccc}
\hline \multirow{2}{*}{ Variáveis } & \multicolumn{2}{c}{ Níveis de inclusão do concentrado nas rações experimentais } & \multirow{2}{*}{ Regressão } & \multirow{2}{*}{ CV \% } \\
\cline { 2 - 4 } & $20 \%$ & $40 \%$ & $60 \%$ & $80 \%$ & & \\
\hline CDMS & 55,29 & 61,09 & 59,97 & 58,26 & $\mathrm{Y}=58,41$ & 5,33 \\
CDMO & 57,19 & 62,02 & 62,07 & 63,99 & $\mathrm{Y}=61,32$ & 6,71 \\
CDPB & 54,76 & 58,96 & 56,94 & 55,48 & 1 & 2,07 \\
CDEE & 77,70 & 81,24 & 84,11 & 80,76 & $\mathrm{Y}=80,79$ & 5,66 \\
CDFDN & 45,85 & 50,25 & 48,50 & 47,71 & $\mathrm{Y}=48,08$ & 5,47 \\
CDFDA & 36,41 & 38,43 & 37,20 & 36,44 & $\mathrm{Y}=37,12$ & 9,28 \\
CDCHT & 43,52 & 49,10 & 48,16 & 50,77 & $\mathrm{Y}=47,89$ & 11,11 \\
CDCNF & 75,42 & 74,70 & 70,93 & 69,65 & $\mathrm{Y}=72,68$ & 11,67 \\
\hline
\end{tabular}

${ }^{1} \mathrm{Y}=49,4330+0,354297 \mathrm{X}-0,00353645 \mathrm{X}^{2}\left(\mathrm{R}^{2}=20,25 \%\right)$;

Fonte: Elaboração dos autores.

O coeficiente de digestibilidade da PB apresentou ponto de máximo para o nível de 50\% de concentrado na dieta, com valores de 58,31\%, respectivamente. Entretanto, Moreno et al. (2010) não observaram efeito $(\mathrm{P}>0,05)$ dos níveis de $40 \%$ e $60 \%$ de concentrado sobre o coeficiente de digestibilidade da PB com valor médio de 78,22\%. Este maior valor observado para o coeficiente de digestibilidade da PB em relação ao presente trabalho, pode ter sido influenciado pelo maior teor de proteína bruta da dieta, que foi de $19 \%$, além das rações que continham uréia em sua composição.

Os dados do presente trabalho corroboram com Moreno et al. (2010), que também não observaram diferença $(\mathrm{P}>0,05)$ entre diferentes níveis de concentrado sobre o coeficiente de digestibilidade da MS, MO, EE, FDN, FDA, e CNF em cordeiros, com valores médios de 77,23\%; 78,79\%; 83,57\%; $44,55 \% ; 35,93 \%$ e $93,53 \%$, respectivamente. Estes maiores valores de coeficiente de digestibilidade da MS, MO, EE e CNF observados por Moreno et al. (2010) em relação ao presente trabalho pode ser devido ao balanceamento das rações experimentais que foram formuladas para atender a exigência de ganho de $300 \mathrm{~g}$ animal ${ }^{-1} \mathrm{dia}^{-1}$ enquanto as rações do presente estudo foram balanceadas para atender ganho próximo a $100 \mathrm{~g}_{\text {animal }}{ }^{-1} \mathrm{dia}^{-1}$.

Os diferentes níveis de concentrado na dieta de cordeiros não influenciaram $(\mathrm{P}>0,05)$ o valor de $\mathrm{pH}$ do líquido ruminal. Porém, o $\mathrm{pH}$ do líquido ruminal diferiu em relação ao tempo após a alimentação de forma quadrática para todas as rações experimentais (Figura 1), em que $\mathrm{pH}=6,978-0,158 \mathrm{X}+0,019 \mathrm{X}^{2}$, $\left(r^{2}=45,01 \%\right)$. 
Figura 1. Estimativa do $\mathrm{pH}$ do líquido ruminal dos cordeiros em função do tempo após a alimentação para os diferentes níveis de concentrado na dieta total.

Estimativa do $\mathrm{pH}$ do líquido ruminal dos cordeiros

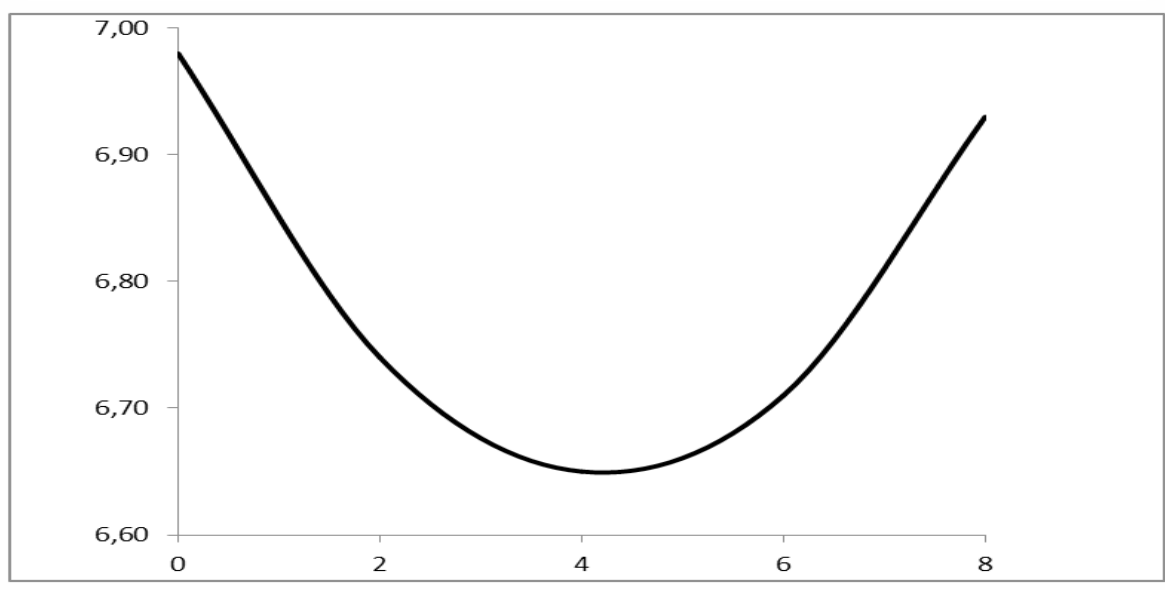

Tempo após alimentação (horas)

Fonte: Elaboração dos autores.

$\mathrm{O}$ valor mínimo médio estimado para o $\mathrm{pH}$ do líquido ruminal foi de 6,64 às 4 horas e 12 minutos após a alimentação e o valor médio do $\mathrm{pH}$ observado foi de 6,80. O menor valor de $\mathrm{pH}$ do líquido ruminal obtidos próximos a 4 horas após a alimentação está de acordo com os dados obtidos por Maeda et al. (2007), os quais observaram que $\mathrm{o} \mathrm{pH}$ do líquido ruminal alcança seu valor mais baixo de 2 a 6 horas após a ingestão do alimento, em decorrência da maior produção de ácidos graxos voláteis proveniente da fermentação dos carboidratos dietéticos no rúmen. A partir desses tempos após a alimentação, os mecanismos de tamponamento do $\mathrm{pH}$ ruminal, tais como a ação da saliva e a absorção de ácidos pelo epitélio ruminal, conseguem contrabalançar a produção de ácidos graxos voláteis.
A inclusão de níveis crescentes de concentrado não alterou $(\mathrm{P}>0,05)$ a concentração do $\mathrm{N}^{-\mathrm{NH}_{3}}$ do líquido ruminal de cordeiros. Entretanto, houve efeito quadrático para o $\mathrm{N}-\mathrm{NH}_{3}$ do líquido ruminal em função do tempo (Figura 2), em que $\mathrm{N}^{-\mathrm{NH}_{3}}=$ $16,420+1,653 \mathrm{X}-0,226 \mathrm{X}^{2}\left(\mathrm{r}^{2}=51,08 \%\right)$.

$\mathrm{O}$ valor médio observado de $\mathrm{N}-\mathrm{NH}_{3}$ do líquido ruminal foi de $17,61 \mathrm{mg} 100 \mathrm{~mL}^{-1}$ de líquido ruminal, o qual manteve-se abaixo da faixa ótima de 19 e $23 \mathrm{mg} 100 \mathrm{~mL}^{-1}$ para a máxima atividade fermentativa ruminal (ZEOULA et al., 2003) e acima da concentração de $5,0 \mathrm{mg} 100 \mathrm{~mL}^{-1}$ estabelecida pela literatura para não limitar o crescimento microbiano. $\mathrm{O}$ valor máximo médio estimado para a concentração de nitrogênio amoniacal do líquido ruminal foi de $19,45 \mathrm{mg} 100 \mathrm{~mL}^{-1}$ obtido as 3 horas e 42 minutos após a alimentação. 
Figura 2. Estimativa da concentração do nitrogênio amoniacal $\left(\mathrm{N}_{-} \mathrm{NH}_{3}\right) \mathrm{mg} 100 \mathrm{~mL}^{-1}$ do líquido ruminal de cordeiros em função do tempo após a alimentação para as diferentes níveis de concentrado na dieta total.

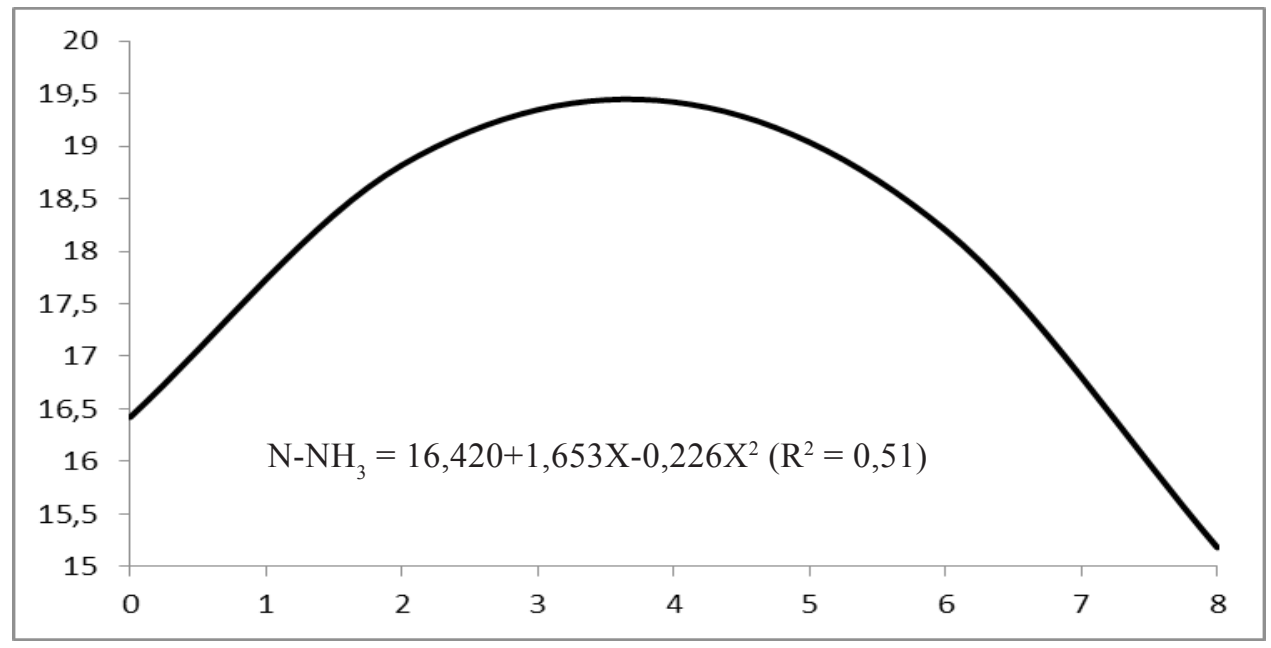

Fonte: Elaboração dos autores.

Os diferentes níveis de concentrado na alimentação de cordeiros não influenciaram $(\mathrm{P}>0,05)$ o valor de temperatura corporal externa (TC) e temperatura retal (TR) de cordeiros (Tabela 5). Da mesma forma, os períodos da manhã e da tarde não influenciaram os valores de TR e TC dos cordeiros.

Tabela 5. Temperatura retal e corporal externa de cordeiros alimentados com diferentes níveis de concentrado.

\begin{tabular}{lccccc}
\hline \multirow{2}{*}{ Período } & \multicolumn{5}{c}{ Variaveis climaticas do ambiente } \\
\cline { 2 - 6 } & TA & TA min & TA max & TBS & TBU \\
\hline Manhã & 22,45 & - & - & 24,40 & 23,20 \\
Tarde & 30,30 & - & - & 40,30 & 26,05 \\
Média & 26,38 & 22,15 & 36,15 & 32,35 & 24,63 \\
\hline
\end{tabular}

Temperatura retal e corporal dos cordeiros

\begin{tabular}{lcccccc}
\hline \multirow{2}{*}{ Temperatura } & \multicolumn{3}{c}{ Níveis de inclusão do concentrado nas rações experimentais } & \multirow{2}{*}{ Regressão } & \multirow{2}{*}{ \% CV } \\
\cline { 2 - 4 } & $20 \%$ & $40 \%$ & $60 \%$ & $80 \%$ & & \\
\hline T. Retal (M) & 38,71 & 38,92 & 39,05 & 38,87 & $\mathrm{Y}=38,89$ & 0,73 \\
T. Retal (T) & 39,61 & 39,66 & 39,72 & 39,64 & $\mathrm{Y}=39,66$ & 0,32 \\
T. Retal med & 39,16 & 39,29 & 39,39 & 39,25 & $\mathrm{Y}=39,27$ & 0,48 \\
T. corporal (M) & 30,66 & 30,99 & 30,63 & 30,39 & $\mathrm{Y}=30,67$ & 2,45 \\
T. corporal (T) & 33,63 & 33,80 & 33,67 & 33,52 & $\mathrm{Y}=33,70$ & 0,63 \\
T. corporal med & 32,25 & 32,39 & 32,15 & 31,95 & $\mathrm{Y}=32,18$ & 1,11 \\
\hline
\end{tabular}

M: período da manhã; T: período da tarde e med: media dos períodos.

Fonte: Elaboração dos autores.

No entanto, pode ser observado na Tabela 5, que a temperatura ambiente apresentou uma variação de $7,85{ }^{\circ} \mathrm{C}$ entre o período da manhã $\left(22,45{ }^{\circ} \mathrm{C}\right)$ e da tarde $\left(30,30{ }^{\circ} \mathrm{C}\right)$. Foi observado variação de $0,77{ }^{\circ} \mathrm{C}$ na TR e de $3,03{ }^{\circ} \mathrm{C}$ na $\mathrm{TC}$ dos cordeiros, respectivamente para os período da manhã e da 
tarde. Esta variação na temperatura ambiente além da TR e TC dos cordeiros entre o período da manhã e da tarde, sugere que o melhor horário para realizar o manejo alimentar de ovinos produzidos em região tropical é o período da manhã, uma vez que pode contribuir na redução do estresse calórico, o qual pode ser causado pelo metabolismo animal e pela temperatura ambiente elevada.

O valor médio observado de TR foi de $39,27^{\circ} \mathrm{C}$ para os diferentes níveis de inclusão do concentrado, estando esses dados de acordo com o observado por Neves et al. (2009), que observaram temperatura retal média de $39,80{ }^{\circ} \mathrm{C}$ para animais da raças Santa Inês, criados a pasto no semi-arredo nordestino.

Eustáquio Filho et al. (2011) observaram que ovinos Santa Inês mantidos em câmara climática a 30 ${ }^{\circ} \mathrm{C}$ apresentaram temperatura retal de $38,70^{\circ} \mathrm{C}$, valor este menor do que o observado no presente estudo. Este fato pode ser devido a temperatura ambiente, a umidade relativa do ar e velocidade do vento na câmara climática serem controlados no estudo de Eustáquio Filho et al. (2011), enquanto no presente trabalho estas variáveis não foram controladas, propiciando maior variação nas temperaturas de máximo e mínimo gerando provavelmente menor conforto térmico aos animais.

A temperatura corporal externa (TC) média foi de $32,18{ }^{\circ} \mathrm{C}$. Este valor ficou 3,14\% acima dos valores observados por Eustáquio Filho et al. (2011), os quais observaram valor de TC de 31,20 ${ }^{\circ} \mathrm{C}$ para ovinos mantidos a temperatura ambiente de $30,00{ }^{\circ} \mathrm{C}$ e alimentados com $75 \%$ de capim elefante e $25 \%$ de concentrado. Esta variação da TC entre os estudos pode ser devido à raça dos animais e ao ambiente natural não controlado no presente estudo.

\section{Conclusões}

Assim conclui-se que a utilização de $38 \%$ de concentrado nas rações contendo a silagem de milho como único volumoso em dietas de cordeiros produzidos na região do Vale do Alto Guaporé favorece o máximo consumo de matéria seca, matéria orgânica e proteína bruta. $\mathrm{O}$ coeficiente de digestibilidade da matéria seca, matéria orgânica, extrato etéreo, fibra em detergente neutro e ácido não são alterados com a adição de até $80 \%$ de concentrado na dieta de cordeiros, bem como não afeta o pH e a concentração de nitrogênio amoniacal do líquido ruminal, temperatura corporal e retal.

\section{Agradecimentos}

A Fundação de Amparo à Pesquisa do Estado de Mato Grosso (FAPEMAT) por ter concedido bolsas de iniciação cientifica aos acadêmicos do Curso de Zootecnia. A Universidade do Estado de Mato Grosso (UNEMAT) - Campus Universitário de Pontes e Lacerda, por ter apoiado e auxiliado no desenvolvimento desta pesquisa cedendo as instalações do Setor de Metabolismo Animal (SeMA) e equipamentos do Laboratório de Análise de Alimentos e Nutrição Animal (LAANA). Ao senhor e senhora Bragatto da fazenda Pau D'Alho por ter fornecido os animais (cordeiros) para execução do presente estudo.

\section{Referências}

BARROS, N. N.; VASCONCELOS, V. R.; ARAÚJO, M. R. A. Influência do grupo genético e da alimentação sobre o desempenho de cordeiros em confinamento. Pesquisa Agropecuária Brasileira, Brasília, v. 38, n. 9, p. 1111-1116, 2003.

BORGES, C. A. A.; RIBEIRO, E. L. A.; MIZUBUTI, I. Y.; SILVA, L. D. F.; PEREIRA, E. S.; ZARPELON, T. G.; CONSTANTINO, C.; FAVERO, R. Substituição de milho grão inteiro por aveia preta grão no desempenho de cordeiros confinados recebendo dietas com alto grão. Semina: Ciências Agrárias, Londrina, v. 32, n. 1, p. 2011-2020, 2011.

CARDOSO, A. R.; CARVALHO, S.; GALVANI, D. B.; PIRES, C. C.; GASPERIN, B. G.; GARCIA, R. P. A. Comportamento ingestivo de cordeiros alimentados com dietas contendo diferentes níveis de fibra em detergente nutro. Ciência Rural, Santas Maria, v. 36, n. 2, p. 604609, 2006. 
CARVALHO, G. G. P.; PIRES, A. J. V.; SILVA, R. R.; VELOSO, C. M.; SILVA, H. G. O. Comportamento ingestivo de ovinos alimentados com dietas compostas de silagem de capim-elefante amonizada ou não e subprodutos agroindustriais. Revista Brasileira de Zootecnia, Viçosa, MG, v. 35, n. 4, p. 1805-1812, 2006. Supelemento.

CASTRO, J. M. C.; SILVA, D. S.; MEDEIROS, A. N.; PIMENTA FILHO, E. C. Desempenho de cordeiros Santa Inês alimentados com dietas completas contendo feno de maniçoba. Revista Brasileira de Zootecnia, Viçosa, $\mathrm{MG}$, v. 36, n. 3, p. 674-680, 2007.

CRUZ, B. C. C.; SANTOS-CRUZ, C. L.; PIRES, A. J. V.; ROCHA, J. B.; SANTOS, S.; BASTOS, M. P.V. Desempenho, consumo e digestibilidade de cordeiros em confinamento recebendo silagens de capim elefante com diferentes proporções de casca desidratada de maracujá. Semina: Ciências Agrárias, Londrina, v. 32, n. 4, p. 1595-1604, 2011.

EUSTÁQUIO FILHO, A.; TEODORO, S. M.; CHAVES, M. A.; SANTOS, P. E. F.; SILVA, M. W. R.; MURTA, R. M.; CARVALHO, G. G. P.; SOUZA, L. E. B. Zona de conforto térmico de ovinos da raça Santa Ines com base nas respostas fisiológicas. Revista Brasileira de Zootecnia, Viçosa, v. 40, n. 8, p. 1807-1814, 2011.

FENNER, H. Method for determining total volatile bases in rumen fluid by steam destilation. Journal of Dairy Science, Champaign, v. 48, n. 4, p. 249-251, 1965.

GERON, L. J.V .; MEXIA, A. A.; GARCIA, J.; SILVA, M. M.; ZEOULA, L. M. Suplementação concentrada para cordeiros terminados a pasto sobre custo de produção no período da seca. Semina: Ciencias Agrárias, Londrina, v. 33, n. 2, p. 797-808, 2012.

GERON, L. J. V.; ZEOULA, L. M.; PAULA, E. J. H.; RUPPIN, R. F.; RODRIGUES, D. N.; MOURA, D. C. Inclusão do caroço de algodão em rações de alto concentrado constituído de co-produtos agroindustriais sobre o desempenho animal em tourinhos confinados. Archives of Veterinary Science, Curitiba, v. 16, n. 3, p. 14-24, 2011.

GIMENES, A. L. G.; MIZUBUTI, I. Y.; MOREIRA, F. B.; PEREIRA, E. S.; RIBEIRO, E. L. A.; MORI, R. M. Composição química e estabilidade aeróbia em silagem de milho preparada com inoculante bacteriano e/ou enzimático. Acta Scientiarum Animal Science, Maringá, v. 28 , n. 2, p. 153-158, 2006.

MAEDA, E. M.; ZEOULA, L. M.; GERON, L. J. V.; BEST, J.; PRADO, I. N.; MARTINS, E. N.; KAZAMA, R. Digestibilidade e características ruminais de dietas com diferentes níveis de concentrado para bubalinos e bovinos. Revista Brasileira de Zootecnia, Viçosa, v. 36, n. 3, p. 716-726, 2007.
MEDEIROS, G. R.; CARVALHO, F. F. R.; FERREIRA, M. A.; BATISTA, A. M. V.; ALVES, K. S.; MAIOR JÚNOR, R. J. S.; ALMEIDA, S. C. Efeito dos níveis de concentrado sobre o desempenho de ovinos Morada Nova em confinamento. Revista Brasileira de Zootecnia, Viçosa, v. 36, n. 4, p. 1162-1171, 2007. Suplemento 1.

MERTENS, D. R. Regulation of forage intake. In: FORAGE QUALITY, EVALUATION, AND UTILIZATION, 1994, USA, Proceedings...USA, Wisconsin: Alliance of Crop, 1994.

MORENO, G. M. B.; SILVA SOBRINHO, A. G.; LEÃO, A. G.; LOUREIRO, C. M. B.; PEREZ, H. L.; ROSSI, R. C. Desempenho, digestibilidade e balanço de nitrogênio em cordeiros alimentados com silagem de milho ou cana-de-açúcar e dois níveis de concentrado. Revista Brasileira de Zootecnia, Viçosa, v. 39, n. 4, p. 853-860, 2010.

NATIONAL RESEARCH COUNCIL - NRC. Nutrient requeriment of beef cattle. 7. ed. Washington: National Academy Press, 1996. 242 p.

Nutrients requirements of sheep. 5.ed. Washington, D.C.: National Academy Press, 1985. 99 p.

NEIVA, J. N. M.; TEIXEIRA, M.; TURCO, S. H. N.; OLIVEIRA, S. M. P.; MOURA, A. A. A. N. Efeitos do estresse climático sobre os parâmetros produtivos e fisiológicos de ovinos Santa Inês mantidos em confinamento na região litorânea do nordeste brasileiro. Revista Brasileira de Zootecnia, Viçosa, v. 33, n. 3, p. 668-678, 2004.

NEVES, M. L. M.; AZEVEDO, M. A.; COSTA, L. A. B.; GUIM, A.; LEITE, A. M.; CHAGAS, J. C. Níveis críticos do índice de conforto térmico para ovinos da raça Santa Inês criados a pasto no agreste do estado de Pernambuco. Acta Scientiarum. Animal Sciences, Maringá, v. 31, n. 2, p. 169-175, 2009.

RIBEIRO, E. L. A.; MIZUBUTI, I. Y.; SILVA, L. D. F.; PAIVA, F. H. P.; SAUSA, C. L.; CASTRO, F. A. B. Desempenho, comportamento ingestivo e características de carcaça de cordeiros confinados submetidos a diferentes freqüências de alimentação. Revista Brasileira de Zootecnia, Viçosa, v. 40, n. 4, p. 892-898, 2011.

SECRETARIA DE ESTADO DE PLANEJAMENTO E DESENVOLVIMENTO ECONÔMICO - SEPLAN. Zoneamento sócio econômico e ecológico do estado de Mato Grosso. Cuiabá: SEPLAN, 2007. Disponível em: $<$ http://www.zsee.seplan.mt.gov.br/divulga $>$. Acesso em: 25 maio 2012.

SILVA, D. J.; QUEIROZ, A. C. Análise de alimentos: métodos químicos e biológicos. 2. ed. Viçosa, MG: UFV, 2002. 178 p. 
SILVA, J. F. C.; LEÃO, M. I. Fundamentos de nutrição de ruminantes. Piracicaba: Livroceres, 1979. 380 p.

SNIFFEN, C. J.; O'CONNOR, J. D.; VAN SOEST, P. $\mathrm{J}$. A net carbohydrate and protein system for evaluating cattle diets II. Carbohydrate and protein availability. Journal of Animal Science, Champaing, v. 70, n. 11, p. 3562-3577, 1992.

UNIVERSIDADE FEDERAL DE VIÇOSA - UFV. Sistema de análises estatísticas e genéticas - SAEG Viçosa: UFV. 1997. 150 p. (Manual do usuário).

VAN SOEST, P. J. Nutritional ecology of the ruminant. 2. ed. London: Constock Publishing Associates, 1994. 476 p.

VAN SOEST, P. J.; ROBERTSON, J. B.; LEWIS, B. A. Methods for dietary fiber neutral detergent fiber, and nostarch polysaccharides in relation to animal nutrition. Journal of Dairy Science, Champaing, v. 74, n. 12, p. 3583-3597, 1991.

VIEIRA, P. F. Efeito do formaldeído na proteção de proteinas e lipídios em rações para ruminantes. 1980. Tese (Doutorado em Zootecnia) - Universidade Federal de Viçosa, Viçosa, MG.
ZAMBOM, M. A.; ALCALDE, C. R.; SILVA, K. T.; MACEDO, F. A. F.; SANTOS, G. T.; BORGHI, E. L.; BARBOSA, E. D. Ingestão, digestibilidade das rações e produção de leite em cabras Saanen submetidas a diferentes relações volumoso:concentrado na ração. Revista Brasileira de Zootecnia, Viçosa, v. 34, n. 6, p. 2505-2514, 2005.

ZEOULA, L. M.; CALDAS NETO, S. F.; GERON, L. J. V.; MAEDA, E. M.; PRADO, I. N.; DIAN, P. H. M. Substituição do milho pela farinha de varredura de mandioca (Manihot esculenta, Crantz) em rações de ovinos: consumo, digestibilidade, balanços de nitrogênio e energia e parâmetros ruminais. Revista Brasileira de Zootecnia, Viçosa, v. 32, n. 2, p. 491-502, 2003.

ZEOULA, L. M.; FERELI, F.; PRADO, I. N.; GERON, L. J. V.; CALDAS NETO, S .F.; PRADO, O. P. P.; MAEDA, E. M. Digestibilidade e balanço de nitrogênio com diferentes teores de proteína degradável no rúmen e milho como fonte de amido em ovinos. Revista Brasileira de Zootecnia, Viçosa, v. 35, n. 5, p. 21792186, 2006. 